\title{
A Responsibility to Promote Leadership: Engineering EnTrepreneurs SPEAK BACK TO RESISTANCE \\ Doug Reeve ${ }^{l}$, Robin Sacks ${ }^{l}$, and Cindy Rottmann ${ }^{l}$ \\ ${ }^{I}$ Institute for Leadership Education in Engineering, Department of Chemical Engineering and Applied Chemistry Faculty of Applied Science and Engineering, University of Toronto doug.reeve@utoronto.ca, robin.sacks@,utoronto.ca, cindy.rottmann@,utoronto.ca
}

\begin{abstract}
Phase one of our Engineering Leadership Project (ELP) revealed engineers' widespread resistance to the idea of leadership [10,11]. To test this claim, we conducted a focus group with engineers who selfidentified as leaders-experienced entrepreneurs. Our qualitative analysis of the resulting transcript resulted in eight themes, one of which we elucidate in this paper"leadership education is the responsibility of engineering educators". Our paper examines this theme and identifies four recommendations for engineering educators.
\end{abstract}

Keywords: entrepreneurship, leadership, engineering education

\section{INTRODUCTION}

Over the past decade, North American accreditation bodies have generated standards highlighting the importance of leadership and professional skill development for graduating engineers [1,3]. A brief review of the engineering leadership literature suggests that faculties of engineering across jurisdictions have begun to support leadership education through individual coursework [5], extracurricular certificates [12], and integrated programs $[7,8,13]$. Some do this through partnerships with the University's business school [7], while others develop faculty-specific initiatives with or without the support of industry partners $[2,4,8,9]$.

While centrally initiated, locally developed curricular reform is a good start, preliminary findings from our study on engineering leadership suggests that many engineers resist the notion of leadership because they experience it as imprecise, impractical, inconsistent with collaboration and elitist $[10,11]$. To test the universality of these findings, we reached out to a group of engineers who self identify as leaders - experienced entrepreneurs.

\section{METHODOLOGY}

This paper draws on findings from a larger mixed method study on engineering leadership - the Engineering Leadership Project (ELP), housed in the Institute for Leadership Education in Engineering (ILead) at the University of Toronto. In particular, the paper is an analytic product of a focus group with six prominent Canadian entrepreneurial engineers. Our objectives for this focus group were two fold: 1) to learn about engineering leadership from an experienced group of leader engineers, and 2) to expose our phase one findings to an expert panel. We deliberately sought out a group of engineers who self identified as leaders to test our somewhat surprising phase one finding that a preponderance of engineers we engaged in ELP focus groups resisted the idea of leadership. The three hour long entrepreneur focus group was transcribed verbatim. We analyzed the resulting 57-page transcript using the constant comparative method [6].

\section{RESULTS \& DISCUSSION}

Eight themes emerged from our findings, one of which we discus in this paper-engineering educators have a responsibility to promote leadership. This theme broke down into four sub-themes, all of which double as recommendations for engineering educators: 1) don't give in to engineering students' resistance to leadership; 2) alter your recruitment strategies so that secondary school students with leadership aspirations see engineering as a viable career path; 3) rehabilitate leadership among engineers by separating good leadership possibilities from bad leadership experiences; and 4) help students gain insights about leadership through open-ended program elements.

\subsection{Do not give in to engineers' resistance!}

The engineering entrepreneurs in our focus group-all of who self-identified as engineers AND as leaders-were surprised and disturbed by our findings of widespread resistance to leadership among engineers in industry. They warned us not to accept these findings, and most importantly not to remove the word "leadership" from our discourse:

I think the risk of not talking about leadership... might have...consequences. I would really want to see more engineers running our city or running our financial institutions or parts of our government, just because of the technical ability and all of the other problemsolving, critical thinking, etc...I don't know how you do it without either using the word leadership or concepts like it. 
Focus group participants trusted our findings, but they thought it behooved us as educators to intervene for the good of the students and for the good of society. The next three sub-themes double as low cost intervention strategies tied to recruitment, conceptual reframing and pedagogy.

\subsection{Recruit students with leadership aspirations}

First, a few of the entrepreneurs encouraged us to visit local high schools to introduce prospective students to our leadership initiatives. They believed this recruitment strategy would help us attract future engineers with leadership aspirations to the profession. Over time, a less resistant cohort of engineering students in the faculty would deflate the collective force behind the persistent belief that leadership and technical problem solving are mutually exclusive processes. Members of our team are currently involved in secondary outreach through workshops and summer institutes geared at high school students.

\subsection{Reframe \& rehabilitate the idea of leadership}

Second, a low cost pedagogical strategy for promoting leadership among students who have already been admitted to the faculty of engineering is for instructors to help students reframe and expand their existing conceptions of leadership:

Here's the thing. I understand what they are saying. The concept of leadership sometimes is very broad and encompassing, but I just think that leadership doesn't mean that it is one person sitting on top of the hill waving a flag. It doesn't mean that.

The entrepreneurs hypothesized that junior engineers who distance themselves from the dual engineer-leader identity might be doing so because of unpleasant experiences with managers who directed them to complete repetitive tasks. Our focus group participants believed that we could rehabilitate the notion of leadership in the minds of students by helping them gain insights about leadership from their life experiences with imperfect leaders while exposing them to positive, inspirational instances of engineers who lead by example. Members of our ILead team are currently helping students reframe and rehabilitate the idea of leadership through curricular and co-curricular programming, guest lectures, panels, CEO lunches, infusion lectures and research. In the coming year, we plan to generate ethical case studies in collaboration with Canadian engineers across disciplines to help students hone their decision-making skills.

\subsection{Help students learn from mistakes}

The final recommendation that emerged from our entrepreneur focus group was to create more experimentation in technical courses and take advantage of the open-ended nature of existing design courses. This strategy is less expensive and more manageable than adding courses to an already packed curriculum, but it requires a certain level of faculty buy-in. A few participants who recalled being stifled by repeated warnings about people dying when engineers made mistakes stressed the importance of an institutional climate supportive of open-ended, problem-based learning. They all thought it was important to allow students to take risks and make mistakes in a supervised setting:

Design projects have some version of [learning from mistakes]...Even if they failed, at least they had an experience of being confronted by the normal engineering problem of starting with something fuzzy and making it real...but this discussion is making me realize that...giving some tools to help navigate these [failures], would be a good idea.

The entrepreneur quoted above realized that the provision of open-ended projects was not enough. Engineering educators interested in supporting students' personal and professional growth must also scaffold student learning through navigation tools and metaanalytic reflection. This pedagogical strategy has been used by a number of our colleagues who teach elective courses and run co-curricular leadership certificate programs, but it has yet to be broadly infused throughout the curriculum.

\section{CONCLUSIONS}

Six leader engineers shared important insights with usmany of which converged on our responsibility to promote leadership development among undergraduate engineering students. These prominent Canadian engineering entrepreneurs diversified our understanding of the traditional career trajectory for engineers and energized our work by sharing their agentic philosophies. It is not enough to describe resistance through illustrative quotations, as we have done in the first phase of our Engineering Leadership Project. We also need to actively oppose it through recruitment efforts directed at future students, open-ended curricular and co-curricular offerings for current students, and rehabilitating the idea of leadership within the engineering profession.

\section{Acknowledgements}

This study was conducted with support from four partner companies. It also received support from the Dean's Strategic Fund at the Faculty of Applied Science and Engineering, University of Toronto. Finally, we are grateful to the engineers, engineering educators and HR professionals who agreed to participate in focus groups and interviews. 


\section{References}

[1] ABET. Criteria for Accrediting Engineering Programs: Effective for Reviews during the 2012-2013 Accreditation Cycle. Baltimore, MD: Engineering Accreditation Commission (EAC), 2011, 24pp. Available as of April 11, 2014 from http://www.abet.org/DisplayTemplates/DocsHandbook.aspx ?id=3143

[2] David J Bayless, "Developing leadership skills in engineering students: Foundational approach through enhancement of self-awareness and interpersonal communication," in Proc. CEEA Canadian Engineering Education Conf., (Montreal, QC; 17-20 June 2013).

[3] CEAB. Canadian Engineering Accreditation Board Accreditation Criteria and Procedures. Ottawa, ON: Canadian Council of Professional Engineers (CCPE), 2012, 114pp. Available as of April 11, 2014 from http://www.engineerscanada.ca/sites/default/files/w Accredi tation Criteria Procedures 2012.pdf

[4] Elizabeth A Croft, Paul Winkelman, Alaya Boisvert and Kristin Patten, "Global engineering leadership: Design and implementation of local and international service learning curriculum for senior engineering students," in Proc. CEEA Canadian Engineering Education Conf., (Montreal, QC; 1720 June 2013).

[5] Greg J Evans, Douglas W. Reeve and Annie E. Simpson, "Introducing leadership learning in engineering classrooms," in Proc. CEEA Canadian Engineering Education Conf., (Kingston, ON; 7-9 June 2010).

[6] Barney Glaser and Anselm Strauss, The Discovery of Grounded Theory. Chicago, IL: Aldine, 1967, 271 pp. \{ISBN: 0-202-30260-1\}

[7] Amy Hsiao, "Developing engineering managers: The master of engineering management program at Memorial University of Newfoundland," in Proc. CEEA Canadian Engineering Education Conf., (Montreal, QC; 17-20 June 2013).
[8] Sherra E Kerns, Richard K. Miller and David V. Kerns. Designing from a blank slate: The development of the initial Olin College curriculum. In NAE (Ed.), Educating the Engineer of 2020: Adapting Engineering Education to the new century. Washington, DC: National Academies Press, 2005, p.98-113.

[9] Amadin Osagiede, Monica Farmer Cox and Benhamin Ahn, "Purdue University's Engineering Leadership Program: Addressing the shortfall of engineering leadership education," in Proc. 120 th ASEE Annual Conference and Exposition, (Atlanta, GA; 23-26 June 2013).

[10] Douglas W. Reeve, Robin Sacks, Cindy Rottmann, Frieda Daniels and Adam Wray, "Engineer leadership in organizations and the implications for curriculum development," in Proc. CEEA Canadian Engineering Education Conf., (Montreal, QC; 17-20 June 2013).

[11] Cindy Rottmann, Robin Sacks and Douglas W. Reeve, "Engineering leadership: Grounding leadership theory in engineers' professional identities," Leadership, Currently under review.

[12] Annie E. Simpson, Douglas W. Reeve and Greg J Evans, "A summer leadership development program for chemical engineering students," Journal of Leadership Education, vol. 11, no. 1, pp. 222-232, 2012.

[13] Karl K Stevens, Tim VanEpps, Sharon M. Schlossberg, Ankur Agarwal and Georgiana L Hamza-Lup, "Innovation leadership honors program: Addressing engineering education needs through curriculum enhancement," in Proc. $39^{\text {th }}$ ASEE/IEEE Frontiers in Education Conference, (San Antonio, TX; 18-21 October 2009). 